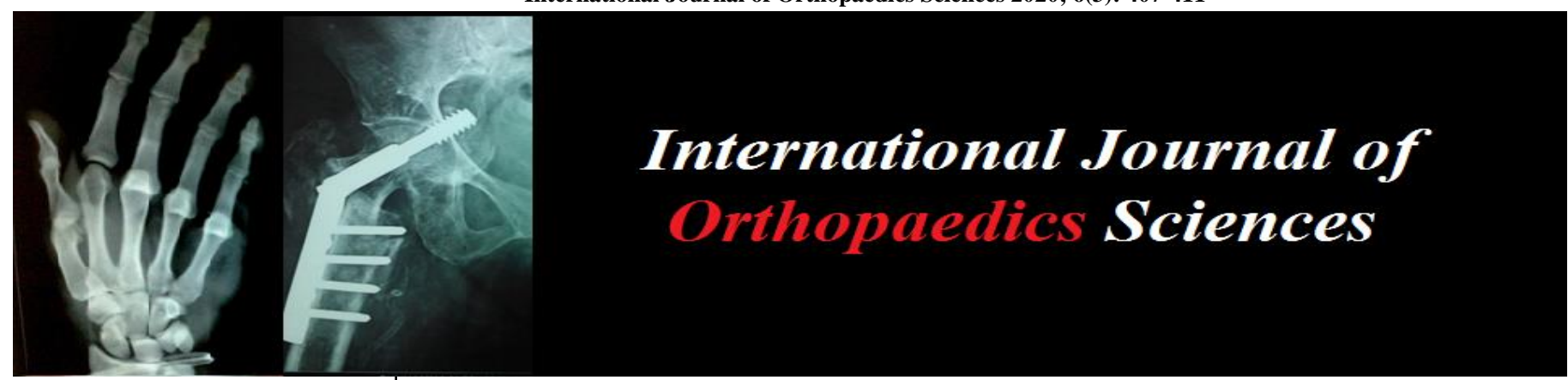

E-ISSN: 2395-1958

P-ISSN: 2706-6630

IJOS 2020; 6(3): 407-411

(C) 2020 IJOS

www.orthopaper.com

Received: 04-05-2020

Accepted: 06-06-2020

Dr. Arvind Kumar K

Karpaga Vinayaga Institute of

Medical Sciences and Research

Center, Maduranthagam,

Tamil Nadu, India

Dr. Arun Kumar Ramanathan Karpaga Vinayaga Institute of Medical Sciences and Research

Center, Maduranthagam,

Tamil Nadu, India
Corresponding Author: Dr. Arvind Kumar K

Karpaga Vinayaga Institute of Medical Sciences and Research Center, Maduranthagam,

Tamil Nadu, India

\section{Minimally invasive percutaneous plate osteosynthesis for closed proximal tibia fractures: A study of 30 cases}

\author{
Dr. Arvind Kumar K and Dr. Arun Kumar Ramanathan
}

DOI: https://doi.org/10.22271/ortho.2020.v6.i3g.2229

\begin{abstract}
Tibial plateau fractures comprises about one percent of all fractures and complex bicondylar fractures comprise of $30 \%$ of all Tibial plateau fractures. Minimally invasive percutaneous plate osteosynthesis [MIPPO] is a method of biological fixation where a plate is percutaneously inserted and fixed at a distance proximally and distally from the site of fracture. By minimal exposure, this aids in the protection of the essential fracture hematoma, minimal soft tissue dissection, avoidance of periosteal stripping and providing a sufficient fixation. So the need for the study is to assess the effectiveness of the technique in achieving fracture union, functional outcome and to know the rate of complications associated with MIPPO. The purpose of this study was to assess the results and the efficacy of MIPPO for of the proximal tibia fracture. This is a prospective study of 30 patients with tibial condylar fractures treated by minimally invasive percutaneous plate osteosynthesis at Karpaga vinayaga institute of medical sciences and research center, Chengalpattu, Tamil Nadu. These patients were followed both clinically and radiologically after surgical fixation. A total of 30 patients with tibial condylar fracture were included in the study. The mean age of the participants was $38.70 \pm 14.14$ years, with $21(70 \%)$ males and $9(30 \%)$ females. In our study containing 30 patients operated by MIPPO, we had $66.67 \%$ had excellent result, $20 \%$ had good results, $6.67 \%$ had fair results and remaining $6.67 \%$ had poor results. In our study it was found that high velocity injuries (type IV - VI) have poorer outcome than low velocity injuries (type IIII). In this way cautious patient selection, careful preoperative planning, delicate and reasonable soft tissue and bone handling, precise contouring of plates and vigorous postoperative rehabilitation and patient education appears to be the key to success of the procedure.
\end{abstract}

Keywords: MIPPO, tibial fracture, closed fracture, Schatzker's classification

\section{Introduction}

\subsection{Tibial fractures}

Tibial plateau fractures comprises about one percent of all fractures and complex bicondylar fractures comprise of $30 \%$ of all Tibial plateau fractures. Seventy-five years back, fractures of the proximal tibia were portrayed as "bumper fractures" since they came about because of low energy pedestrian versus vehicle bumper accidents ${ }^{[1]}$. Presently, most of such fractures are auxiliary to highvelocity wounds like high speeding motor vehicle or tumbles from heights. The complex tibial plateau fractures coming about because of direct force high-velocity injuries traditionally portrayed as "explosion or shattered" fractures ${ }^{[1]}$. These fractures represent an inborn trouble in treatment because of the degree of soft tissue injury, fracture comminution, instability, displacement of articular fragments and increased risk of compartment syndrome ${ }^{[2]}$. Closed administration of these complex fractures with cast bracing and traction commonly has been incapable in decreasing and keeping up the congruency of the articular surface and axial alignment leading to mal-union and secondary degenerative arthritis. Despite the fact that anatomical reduction is conceivable with customary techniques for treatment, for example, open reduction and internal fixation, this strategy has been related with countless soft tissue injury and fixation failure ${ }^{[2]}$. This constantly prompts compromise of the overlying soft tissue envelope and results in soft tissue necrosis and profound injury infections. To keep away from such tragic incidence and maintain adequate bony reduction, the concept of Biological Fixation was created. The target of Biological fixation is to help the physiological procedure of bone healing shrewdly and ideally with a negligible measure of operative intervention ${ }^{[2]}$ 


\subsection{MIPPO}

In the nineteenth century, various upgrades and improvements over every clinical forte occurred, simultaneously propels in the field of fracture fixation also occurred, consequently improving the result for function and quality of life of patients with fractures ${ }^{[3]}$. While the healing progress of bone fractures plainly profited by the strategy for plate and screw fixation construct, in 1995, a new application of plate fixation started Minimally invasive percutaneous plate osteosynthesis (MIPPO) ${ }^{[3]}$. MIPPO has been developed as a method of fracture fixation with which the soft tissue envelope around the fracture is preserved and the fracture biology is less affected. The plate is placed through small incisions with as limited dissection and stripping of the soft tissue envelope as possible. This technique has many biological advantages compared to the traditional open reduction and internal fixation ${ }^{[3]}$. MIPPO involves minimal soft tissue dissection with preservation of the vascular integrity of the fracture as well as preserving the osteogenic fracture haematoma. However, the MIPPO technique faces some significant drawbacks. Because of its closed fashion without direct sight and overview of the fracture and the implant manipulations, it requires training, manual skills and surgical experience to adequately perform the procedure ${ }^{[4]}$.

\subsection{Other methods and their complications}

The conventional strategy for ORIF (Open reduction internal fixation) requires wide exposure of the fracture site with depriving of the delicate tissues, which may devascularise the fracture fragments ${ }^{[5]}$. This may add to delayed healing and infections brought about by injury and thus increment the dangers for postponed recuperating and contamination. Open methods involve a bigger incision, all the more draining and a requirement for periosteum stripping during surgical procedure ${ }^{[5]}$. Postoperative recuperation is likewise extended. This procedure was created to evade broad introduction of the fracture site and to limit delicate soft tissue injury, and involves a smaller incision bringing about a smaller scar and recuperation of the delicate tissue happens all the more quickly.

\subsection{Purpose of study}

Minimally invasive percutaneous plate osteosynthesis [MIPPO] is a method of biological fixation where a plate is percutaneously inserted and fixed at a distance proximally and distally from the site of fracture ${ }^{[6]}$. By minimal exposure, this aids in the protection of the essential fracture hematoma, minimal soft tissue dissection, avoidance of periosteal stripping and providing an sufficient fixation. So the need for the study is to assess the effectiveness of the technique in achieving fracture union, functional recovery and to know the rate of complications associated with MIPPO. The purpose of this study was to assess the results and the efficacy of MIPPO for of the proximal tibia fracture.

\section{Material and methods}

\subsection{Study design}

This is a prospective study of 30 patients with tibial condylar fractures treated byminimally invasive percutaneous plate osteosynthesis at Karpaga vinayaga institute of medical science and research centre, chengalpattu from 2017 to 2019. These patients were followed both clinically and radiologically after surgical fixation for six months. Functional outcome was evaluated based on Rasmussen"s criteria $^{[7]}$.

\subsection{Inclusion criteria}

Individuals aged above 18 years of gender, closed fractures, fracture with duration of one week, Schatzker's type 1, 2,3,4,5, and 6 fractures, associated ligamentous injuries and associated fibular upper end fracture.

\subsection{Exclusion criteria}

Individuals aged below 18 years, compound fractures, individuals with other limb fractures and diseases, pathological fractures, associated neurovascular injury and patients who are medically not fit for surgery were excluded from the study.

\subsection{Preoperative procedure}

Patients who were chosen for the surgery were assessed with Anteroposterior and horizontal radiographs of the knee joint, CT scan of the knee joint (not obligatory for all) and MRI of the knee joint (if necessary to preclude ligamentous injury) The ethical clearance was obtained for this study from institutional ethical committee. When the surgical procedure was arranged, the following were routinely followed.

1. Routine preoperative examinations, treatment of the comorbidities of the patient were conducted with proper references to the concerned specialties.

2. Fitness for the medical procedure was taken from the doctors.

3. Utilization of antibiotics pre-operatively and proceeded till the removal of sutures. Joint stability was evaluated under sedation. All cases were performed under fluoroscopic guidance.

\subsection{Operation technique}

The surgical procedure was performed with the patient under general anaesthesia or spinal/epidural. The patient was set supine on a radiolucent fracture table with the affected extremity in longitudinal traction. A pneumatic tourniquet sleeve with satisfactory cushioning was applied to the proximal thigh. The limb was completely cleaned basically with betadine or chlorhexidine scrub solution, painted and draped. The operative site and uncovered parts were secured with a sterile towel and the limb exanguinated with a sterile Esmarchs bandage and the tourniquet inflated, after which the operative site was painted with betadine and afterward with surgical spirit. In specific cases, percutaneous k-wires were acquainted to help in fracture alignment. A proximal tibial locking plate or a $\mathrm{T}$ - Buttress/L - Buttress locking plate of appropriate length was taken. An entry point was made as extensive as essential either medially or laterally, to help insert the plate, which is with caution slid in the sub muscular plane, extraperiosteally. Most extreme consideration was taken in taking care of soft tissue with as minimal dissection and judicious use of retractors as possible. Normal valgus and rotational alignment was checked. Cancellous and cortical screws were suitably used to make sure about the plate proximally and distally. These were inserted percutaneously through little stab incisions focused over the plate holes. An intensive wash with saline and betadine was given, and the wound closed. A sterile dressing was applied and the tourniquet deflated ${ }^{[8,9]}$.

\subsection{Statistical analysis}

Descriptive statistics were reported as mean (SD) for continuous variables, frequencies (percentage) for categorical variables Data were statistically evaluated with IBM SPSS Statistics for Windows, Version 20.0., IBM Corp., Chicago, IL. 


\section{Results}

Table 1: Demographic profile of the study participants $(\mathrm{N}=30)$

\begin{tabular}{|c|c|c|c|}
\hline Sl. no & Variable & Frequency & Percentage \\
\hline 1 & $\begin{array}{l}\text { Gender } \\
\text { Male } \\
\text { Female }\end{array}$ & $\begin{array}{c}21 \\
9\end{array}$ & $\begin{array}{l}70 \\
30\end{array}$ \\
\hline 2 & $\begin{array}{l}\text { Occupation } \\
\text { Laborers } \\
\text { Housewives } \\
\text { Students } \\
\text { Employees } \\
\text { Businessman } \\
\end{array}$ & $\begin{array}{l}11 \\
8 \\
5 \\
3 \\
3 \\
\end{array}$ & $\begin{array}{c}36.7 \\
26.6 \\
16.7 \\
10 \\
10 \\
\end{array}$ \\
\hline 3 & $\begin{array}{c}\text { Schatzker's classification } \\
\text { Type I } \\
\text { Type II } \\
\text { Type III } \\
\text { Type IV } \\
\text { Type V } \\
\text { Type VI }\end{array}$ & $\begin{array}{l}5 \\
9 \\
1 \\
5 \\
8 \\
2\end{array}$ & $\begin{array}{c}16.7 \\
30.3 \\
3.3 \\
16.7 \\
26.7 \\
6.7\end{array}$ \\
\hline 4 & $\begin{array}{c}\text { Side of fracture } \\
\text { Right } \\
\text { Left }\end{array}$ & $\begin{array}{l}20 \\
10\end{array}$ & $\begin{array}{l}66.7 \\
33.3\end{array}$ \\
\hline 5 & $\begin{array}{c}\text { Associated injury } \\
\text { ACL } \\
\text { MCL }\end{array}$ & $\begin{array}{l}2 \\
2\end{array}$ & $\begin{array}{l}6.67 \\
6.67\end{array}$ \\
\hline 6 & $\begin{array}{c}\text { Outcome } \\
\text { Excellent } \\
\text { Good } \\
\text { Fair } \\
\text { Poor }\end{array}$ & $\begin{array}{c}20 \\
2 \\
6 \\
2\end{array}$ & $\begin{array}{c}66.7 \\
6.7 \\
20 \\
6.7 \\
\end{array}$ \\
\hline
\end{tabular}

\subsection{Demographics}

A total of 30 patients with tibial condylar fracture were included in the study. The mean age of the participants was $38.70 \pm 14.14$ years, with $21(70 \%)$ males and $9(30 \%)$ females. Out of 30, $11(36.7 \%)$ were working as laborers, 8 (26.6\%) were housewives, and $5(16.7 \%)$ are students and, remaining three $(10 \%)$ were working as employees and businessman respectively. Demographic characteristics are summarized in Table 1.

\subsection{Schatzker's classification of fracture}

In our study out of 30 cases, most of them presented with right sided fracture $(66.7 \%, \mathrm{n}=20)$. The majority of the fractures were of type II (30\%) and type V (26.7\%) which is cleavage with depression fractures and bicondylar fractures respectively. (Figure 1)

\section{Schatzker's type of fracture}

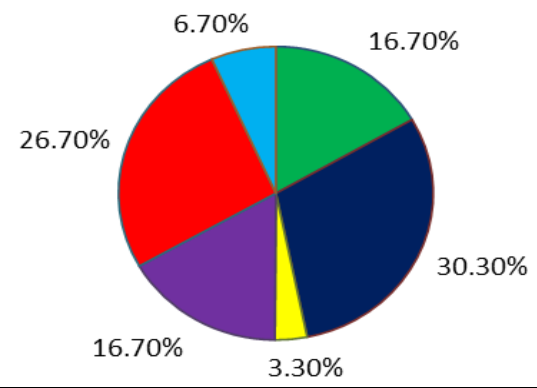

$\square$ Type I
"Type II
$\square$ Type III
$\square$ Type IV
$\square$ Type V
$\square$ Type VI

Fig 1: Schatzker's classification of fracture among the study participants $(\mathrm{N}=30)$

\subsection{Associated injuries}

There were two cases of medial collateral ligament injury and two cases of anterior cruciate ligament injury being reported in this study. Medial collateral ligament were surgically repaired during the surgery. Anterior cruciate ligament injury were not reconstructed because of patient refusal

\subsection{Period of immobilization in weeks}

The mean period of immobilization is $2.63 \pm 1.27$ weeks. Immobilization is ranging from minimum 1 week to maximum of 6 weeks.Most of the cases had good range of painless knee motion $\left(0-130^{\circ}\right)$, with exception for the two patients who developed knee stiffness.

\subsection{Complications}

All fractures united within anticipated time. There was not a single case of nonunion noted in our study. Average time taken for union was $14.00 \pm 1.02$ weeks, ranging from minimum of 10 weeks to maximum of 22 weeks. There were only two cases of wound infection in our study which was associated with knee joint stiffness.

\subsection{Functional outcome}

Functional outcome was assessed based on Rasmussen"s criteria ${ }^{[7]}$. In our study containing 30 patients operated by MIPPO, we had $66.67 \%$ had excellent result, $20 \%$ had good results, $6.67 \%$ had fair results and remaining $6.67 \%$ had poor results (Figure 2). In our study it was found that high velocity injuries (type IV - VI) have poorer outcome than low velocity injuries (type I-III).

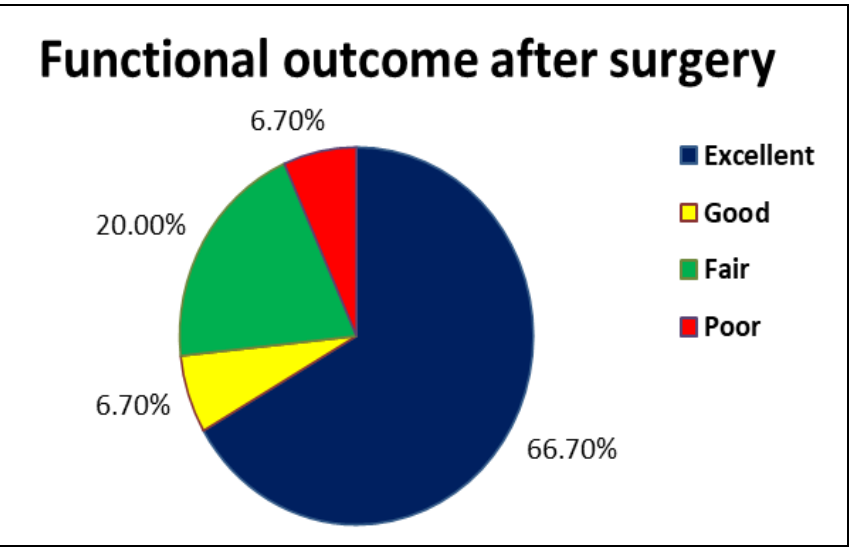

Fig 2: Functional outcome based on Rasmussen"s criteria among the study participants $(\mathrm{N}=30)$

\section{Discussion}

\subsection{Demographics}

Most of fractures happen between the age of 20 and 50 years with greatest rate being including the young age between 2030 years $(40 \%)$. The mean age of the participants in our study was $38.70 \pm 14.14$ years, ranging from 20 to 70 years. Similar results reported by Boune et al. ${ }^{[10]}$ likewise found that most of the patients were between 15-55 years with a mean of 38.5 years. Seppo et al. ${ }^{[11]}$ reported age between $20-60$ years with a mean of 39.8 years which connects with the present study.3 In our study there were about $21(70 \%)$ males and $9(30 \%)$ females. This can be credited to our Indian society where the female population work to a greater extent indoor and hence less inclined injury. So the huge extent of tibial plateau fracture related sex dissemination was not accessible for remarks. Occupationally tibial plateau fracture was found in individuals with elevated level of activity like laborers. In our study out of $30,11(36.7 \%)$ were working as laborers, 8 $(26.6 \%)$ were housewives, and $5(16.7 \%)$ are students and, remaining three $(10 \%)$ were working as employees and businessman respectively. Most of them presented with right sided fracture $(66.7 \%)$. 


\subsection{Schatzker's fracture}

Tibial condyle fracture particularly those because of high velocity [Schatzker type IV, V] and those isolating the tibial metaphysis from the diaphysis [Schatzker type VI] are naturally temperamental wounds related fracture comminution, displacement, severe soft tissue injury and a higher frequency of complication ${ }^{[12]}$. Closed treatment of these fractures has brought about a high level of unsuitable outcomes [up to 70\%] as observed in long term follow up in different studies ${ }^{[13]}$. The most generally utilized strategy for treatment of displaced Tibial fracture has been open reduction and internal fixation ${ }^{[14]}$. The principle center around this methodology was the reclamation of the articular surface to as close to anatomical position as could be expected under the circumstances and to keep up the reduction while early knee joint mobilization is initiated. This rigid fixation is, in any case, conceivable simply after soft tissue dissection. Because of the relationship of soft tissue wounds with these fractures, extra soft tissue stripping engaged with open reduction and internal fixation regularly render bony sections avascular and furthermore significantly increase the possibility of infection [15].

\subsection{Functional outcome}

Moore et al ${ }^{[16]}$ in his study revealed a $23 \%$ frequency of infection after ORIF in these complicated fracture. Mallik et al. ${ }^{\text {[17] }}$ reported 4 of his 5 cases being contaminated after ORIF. Anger et al. ${ }^{[18]}$ detailed of profound disease in 7 out of 8 fractures that were treated with an medial plate. To restrict the degree of soft tissue injury not withstanding the soft tissue damage related with these intricate fractures, minimally invasive biological fixation procedures have advanced throughout over the recent few decades. Among these methodologies, minimally invasive percutaneous plate osteosynthesis (MIPPO) conceivably has become a decent alternative in the treatment of these complex fractures ${ }^{[7]}$. In our study containing 30 patients operated by MIPPO, we had $66.67 \%$ had excellent result, $20 \%$ had good results, $6.67 \%$ had fair results and remaining $6.67 \%$ had poor results (Table 2 ). Delay in medical procedure was essentially because of the nearness of abrasions over the operative site; consequently medical procedure was performed simply after the abrasions healed ${ }^{[19]}$

Table 2: Comparison of functional outcome from different articles

\begin{tabular}{|c|c|c|c|c|c|c|c|}
\hline SI no & Author & Year & Number of cases & Excellent & Good & Fair & Poor \\
\hline 1 & Gupta et al. ${ }^{[20]}$ & 2020 & 30 & $43.33 \%$ & $40 \%$ & $16.66 \%$ & - \\
\hline 2 & ${\text { Dhotkar } \text { et } \text { al. }{ }^{[21]}}^{212}$ & 2019 & 20 & $50 \%$ & $25 \%$ & $16.6 \%$ & - \\
\hline 3 & Vickas et al. $^{[2]}$ & 2019 & 30 & $47 \%$ & $33 \%$ & $17 \%$ & $3 \%$ \\
\hline 4 & ${\text { Girota } \text { et } \text { al. }{ }^{[23]}}^{23}$ & 2019 & 38 & $53.3 \%$ & $36.7 \%$ & $10 \%$ & - \\
\hline 5 & Present study & 2020 & 30 & $66.7 \%$ & $6.7 \%$ & $20 \%$ & $6.7 \%$ \\
\hline
\end{tabular}

\subsection{Complications}

We fortunately encountered only two cases $(6.67 \%)$ of wound infection which were associated with stiffness of the knee joint. The prolonged immobilization and postponement in surgical procedure were most likely contributory to the advancement of knee stiffness. Krettek et al. ${ }^{[24]}$ detailed one case of infection for which he did a wound debridement and resuturing and leaving the implant in situ. In our study the mean period of immobilization is $2.63 \pm 1.27$ weeks. Immobilization is ranging from minimum 1 week to maximum of 6 weeks. Most of the cases had good range of painless knee motion $\left(0-130^{\circ}\right)$, with exception for the two patients who developed knee stiffness. In another study [25] they reported out of 58 proximal tibia fracture by this procedure, they got better outcomes in $78 \%$ of the patients. Studies by chang-wug et al. ${ }^{[26]}$ have indicated the helpful impacts of this method in proximal tibial fractures. Additionally faster postoperative recovery capacity has been exhibited in these fractures utilizing the strategy of biological plate fixation. There was no frequency of nonunion in our examination. Gupta et al. [20] revealed preservation of extraosseous blood supply and decreased the danger of nonunion. In the study directed by Krettek et al. ${ }^{[24]}$, no instances of delayed or nonunion were recorded.

\section{Conclusion}

In this way cautious patient selection, careful preoperative planning, delicate and reasonable soft tissue and bone handling, precise contouring of plates and vigorous postoperative rehabilitation and patient education appears to be the key to success of the procedure.

\section{References}

1. Madhor A Karunakar, Micheal J Bose. Rockwood and
Greens "Fracture in adults". 5th edition, 2001

2. Newman SD, Mauffrey CP, Krikler S. Distal metadiaphyseal tibial fractures. Injury. 2011; 42:975-84.

3. Lau TW, Leung F, Chan CF, Chow SP. Minimally invasive plate osteosynthesis in the treatment of proximal humeral fracture. Int Orthop. 2007; 31:657-64.

4. Zhiquan A, Bingfang Z, Yeming W, Chi Z, Peiyan H. Minimally invasive plating osteosynthesis (MIPO) of middle and distal third humeral shaft fractures. J Orthop Trauma. 2007; 21:628-33.

5. Frigg R. Locking compression plate (LCP): an osteosynthesis plate based on the dynamic compression plate and point contact fixator (PCFix) Injury. 2001; 32(Suppl 2):636.

6. Apivatthakakul T, Arpornchayanon O. Minimally invasive plate osteosynthesis (MIPO) combined with distraction osteogenesis in the treatment of bone defects. A new technique of bone transport: a report of two cases. Injury. 2005; 36(4):530-538. doi: 10.1016/j.injury.2004.05.036.

7. Rasmussen p.s tibial condylar fractures. Impairment of knee joint stability as an indication for surgical treatment. $\mathrm{J}$ bone and joint surgery. 1973; 55:1331-1350

8. DiPasquale T, Mast JW. Indirect reduction and Percutaneous screw fixation of displaced tibial plateau fractures. J Orthop Trauma. 1992; 63(3):340-6.

9. Mast J, Jakob R, Ganz R. Planning and reduction technique in fracture surgery. Berlin; Springer Verlag; 1989, 254.

10. Bourne R, Rorabeck C, Macnab J. Intra-articular fractures of the distal tibia: The pilon fracture. J Trauma $1983 ; 23: 591-596$.

11. Seppo H. Indications for surgical treatment of tibial condyle fractures. Clin Orthop 1994; 302:199-205 
12. Rockwood CA. Rockwood and Green's - Textbook of fractures in adults. Volume 1. 5th edition. 2001, 191.

13. Apley AG. Fractures of the lateral tibial condyle treated by skeletal traction and early mobilization. A review of 60 cases with special reference to long term results. J Bone Joint Surg. 1956; 38B:699.

14. Shelton WR, Sage FP. Modified Nicoll graft. Treatment of gap nonunion in the upper extremity. J Bone Joint Surg. 1981; 63(2):226-31.

15. Barrington T, Dewar F. Tibial plateau fractures. Can J Surg. 1965; 8:146.

16. Moore TJ, Watson T, Green SA et al: Complications of surgically treated supracondylar fractures of the femur. J Trauma. 1987; 27: 402-406,

17. Malik AL, Siddique M, Niazi NS, Niazi SN. Outcome of locking compression plate in supracondylar fracture of distal femur by minimally invasive plate osteosynthesis. Pakistan J Med Heal Sci. 2015; 9(1):31-.

18. Anger R. Critical intraarticular fractures of the proximal tibia. Rev Chir Orthop. 1968; 54:259.

19. Burn C, Bartzka G, Coldeway J, Muggler E. Fractures of the tibial plateau. Clin Orthop. 1979; 138:84.

20. Gupta AD, Daveshwar RN, Solanki JJ. A study of extra articular metaphyseal proximal tibia fractures treated with proximal tibia plate using MIPPO technique. International Journal of Orthopaedics. 2020; 6(2):27-30.

21. Dhotkar KS, Samal S, Sahoo SK. Comparison between plating by MIPPO and IMLN in proximal tibia extraarticular fractures: Our experience at a tertiary care hospital.

22. Vickas J, Mudabbir MS, Kamal SK, Sriharsha Y, Arun M, Nagnur MI. The functional and radiological outcome of minimally invasive percutaneous plate osteosynthesis (MIPPO) in treatment of distal meta-physeal fractures of tibia. International Journal of Orthopaedics. 2020; 6(1):995-8.

23. Girotra P, Singh NK, Kumar S. Functional outcome of locking compression plate in the management of proximal tibia fracture. International Journal of Orthopaedics. 2020; 6(1):152-6.

24. Krettek C, Gerkfa T, Miclau T. A minimally invasive medial approach for proximal tibial fractures. Injury. 2001; 32(1):SA4-13

25. Hazarika S, Chakravarthy J, Cooper J. Minimally invasive locking plate osteosynthesis for fractures of the distal tibia- Results in 20 patients. Injury. 2006; 37:877887.

26. Chang-Wug Oh, Jong-Keon Oh, Hee-Soo Kyung, In-Ho Jeon1, Byung-Chul Park, Woo-Kie Min1 et al, Double plating of unstable proximal tibial fractures using minimally invasive percutaneous osteosynthesis technique, Acta Orthopaedica. 2006; 77(3):524-530. 